Journal of the Scholarship of Teaching and Learning, Vol. 21, No. 2, June 2021, pp. 144-146.

doi: 10.14434/josotl.v21i2.32982

\title{
Audio Guides for Digital Archives
}

\author{
Kate Holterhoff \\ Georgia Institute of Technology
}

There has never been a better time to create audio content than the present. Not only do most personal computers come with audio software like GarageBand (OSX) and VoiceRecorder (Win) already installed, free programs such as Audacity and LMMS can be readily downloaded online. This has opened up a variety of new project opportunities for instructors eager to incorporate digital humanities concepts and ideas into their classrooms. In multimodal communication courses foregrounding history, archive, and visual culture studies, the form of the audio guide offers a useful medium for students to create inventive and theoretically rigorous projects.

Defining the structure and intent of audio guides poses many challenges. Generally these recordings are site specific; they range in length from between one and ten minutes, and they include summary and analysis of a specific object in an institutional collection. Audio guides point out critical, historical, and aesthetic details that viewers might miss without curation. The best guides combine storytelling with argumentation. They are intended to make the experience of visiting museums or historical sites more informative and entertaining. For this reason, these institutions hire professional narrators, musicians, and writers to compose compelling guides for the public. In the past, uncomfortable headphones and bulky players (usually worn around the neck) were the only means of experiencing this content. Now, many patrons access these guides using their smartphones to stream the content from a website or else download an interactive app. While the affordances of audio guides - their function, content, and medium - represent a moving target, flexibility makes these texts useful as assignments in the humanities classroom.

Although many people, and especially those under forty, consider audio guides to be boring, academic, and old-fashioned, in the experience of myself and other instructors at the Georgia Institute of Technology, the prospect and process of writing, directing, and recording guides energizes undergraduate students. I have found this to be especially true for guides created to accompany digital content. With the number of online databases for archives, museums, and libraries growing every year, there is ample opportunity to design an audio guide assignment that compliments the collections of art, history, or science museums; archives for significant writers, politicians, and artists; and library special collections containing historic texts, photographs, manuscripts, or other ephemera. Collections accessible online through high-resolution photos and informative metadata descriptions (for example, the Rossetti Archive, Whitman Archive, and Smithsonian Museum) are invaluable resources in the classroom. Although digital collections can never replace the embodied experience of seeing historical objects in person, using online source material alleviates the logistical issues of transportation and mobility for students. Digital collections enable students to experience their objects of study from the comfort of their homes, dorm rooms, or local libraries. It can also simplify the process of submitting and sharing these projects.

Rather than asking students to upload audio files to a course management site (Blackboard, Canvas, etc.) - admittedly the easiest method-I recommend challenging students to act as public intellectuals by posting their completed guides online. Instructors should have students sign a FERPA disclosure and should not require them to associate their names with their guides. I have identified three primary ways to post projects online. The best method involves uploading guides to SoundCloud or Bandcamp and posting links to the archive's comment form (if available). The advantage of this approach is its separation of the site's mission from the content of the guides (which may be lacking in the sophistication of argument, research, and audio quality). Alternatively, instructors may choose 
to distribute their students' guides through a course website, which links one-directionally to specific pages in the archive. Although few visitors to that archive are likely to discover these projects because there is no avenue to direct visitors to this stand-alone website, this method is most appropriate for creating a pedagogical resource surveying the entire class's output. Finally, instructors may also consider collaborating with the host archive, museum, or library to embed guides directly into the official webpage. Files may be hosted internally or externally, using an app like SoundCloud, Bandcamp, or SoundCite JS (a tool developed by Northwestern University's Knightlab) for adding clickable audio files into inline text. This approach will work best for graduate students able to create high-quality projects and who will benefit professionally by collaborating with outside institutions.

\section{Case Study: Visual Haggard}

Students enrolled in my communication course themed around visual culture, digital archives, and the popular Victorian novelist H. Rider Haggard, created public facing and scholarly audio guides intended to augment the experience of visitors to Visual Haggard (www.visualhaggard.org), a digital archive I direct that preserves, centralizes, and improves access to illustrations created to accompany Haggard's novels. The site currently archives approximately 2,000 images and recently joined the federated sites on NINES, the Networked Infrastructure for Nineteenth-Century Electronic Scholarship. Students engage with the process of audio guide creation for Visual Haggard in order to meet three primary learning objectives. This project asks students to first, conduct substantive research; second, articulate an argument using the oral and nonverbal means of communication; and third, perform close reading to identify a text's underlying assumptions. I curated a sampling of the best projects by uploading them to my SoundCloud account and then posting these to the Disqus comment application on Visual Haggard. (Figure 1)

For this assignment, students wrote scripts and recorded four to seven-minute audio guides to accompany one illustration from Visual Haggard. These guides demonstrate research on nineteenthcentury culture and illustration studies, as well as substantial knowledge about the novel that this illustration accompanies. Individuals selected their illustrations from our class novel, King Solomon's Mines (1885), or any other of Haggard's fifty novels, as long as the student read the novel independently for an earlier assignment. All guides must include the following components:

1. An introduction stating the student's name (optional) and ethos ("I am a student at Georgia Tech enrolled in Dr. Kate Holterhoff's English 1102 course”).

2. A one to two-sentence summary of the novel.

3. A brief biography about the illustrator.

4. A close reading of details in the image.

5. An analysis of the critical implications of this image. How does this illustration and Haggard's text both reflect and push back against late-19th and early-20th-century ideas concerning gender, race, imperialism, environmentalism, etc.? Students select one critical idea to focus on.

6. Cite at least two scholarly secondary sources.

Students peer-reviewed and revised their scripts prior to recording their finished guides. They then uploaded audio guide files, polished scripts, and a reflection about their process to our course management site for possible inclusion on Visual Haggard.

The close reading portion of these projects empowered students to generate exceptionally argued and researched analysis. For an illustration depicting an elephant hunt, one student adopted an environmental justice perspective to critique the image by providing a detailed history and cultural

Journal of the Scholarship of Teaching and Learning, Vol. 21, No. 2, June 2021. josotl.indiana.edu 
analysis of the ivory trade. For an illustration depicting the wicked Zulu witch Gagool, another student provided a sympathetic interpretation of this character, citing Haggard's prejudices to reevaluate this stereotypical antagonist. All of these readings augment the experience of visitors to Visual Haggard by contextualizing the often challenging illustrations archived on the site.

One of the greatest strengths of this project is its facilitation of interdisciplinary collaboration at an instructor's home institution. For my course, this project provided opportunities to team up with instruction librarians, digital archivists, and special collections librarians. I recommend devoting class time to teaching at least one audio manipulation program to students. For example, in the weeks preceding the project due date, an instruction librarian taught my students how to use Audacity. Archivists and special collections librarians are also useful participants in this project for defining the term 'archive,' explaining the function of digital records, and discussing differences between physical and digital collections. Meeting professional archivists makes the experience of working with digital archives especially memorable and engaging. STEM students in particular are often interested, surprised, and delighted by ideas of archive records management and technological innovation in these fields.

Assigning a particular audio guide example at a local institution can offer valuable scaffolding for this project. To ensure that all students had some familiarity with audio guides - and to combat preconceived ideas about the audio guide form - my students prepared for this task by experiencing the Acoustiguide Tour for the exhibit "Cross Country: The Power of Place in American Art 19151950" at the High Museum of Art. Ginia Sweeney, the High's Coordinator of Museum Interpretation, participated meaningfully in the process of these students' guides by attending seminars at Tech to teach students about the history and mission of the High Museum, review the script for Cross Country, and explain the complex audio guide creation process. Students enjoyed meeting a professional audio guide creator, and they benefitted from having access to a polished script prior to composing their own. In fact, we devoted several class sessions to critiquing this sample and thinking about the rhetorical situation of online versus physical guides.

Although the guides produced for my course focus on objects from visual culture, the general structure for this project is ideal for assigning guides that concern a broad range of objects, such as letters, manuscripts, maps, videos, and sheet music. I encourage instructors to adapt this assignment to generate exciting audio guides for their own multimodal and digital humanities courses.

Journal of the Scholarship of Teaching and Learning, Vol. 21, No. 2, June 2021. josotl.indiana.edu 